\title{
SER PESCADOR ARTESANAL: INVESTIGACIÓN ETNOGRÁFICA Y MEDIOS AUDIOVISUALES EN LA COSTA ESTE DE URUGUAY
}

\author{
Being a Fishworker: ethnographic research and media \\ on the East coast of Uruguay.
}

\section{LETICIA D'AMBROSIO CAMARER*}

\section{Fecha de recepción: 29 de diciembre de 2015- Fecha de aprobación: 4 de abril de 2016}

\section{Resumen}

El propósito central de este artículo es analizar el proceso de incorporación de los medios audiovisuales en la investigación etnográfica y cómo a través de dicho registro se consiguió percibir qué es "ser pescador artesanal". Nos proponemos analizar la técnica de registro audiovisual y la producción del documental como forma de representación de un grupo de pescadores artesanales y en particular reflexionaremos sobre el proceso de construcción del relato audiovisual etnográfico, y sus implicancias sociales y políticas. Los resultados de ese proceso de cuatro años de "mirar", "escuchar", registrar, escribir y editar, fue un audiovisual y un libro "El mundo sumergido. Una investigación antropológica de las pesquerías del Mejillón en Piriapolis y Punta del Este" (D'Ambrosio, Lembo, Amato \& Thompson, 2010), que proponen discursos paralelos y polifónicos, generados a partir del trabajo de campo con trabajadores de las pesquerías artesanales en dos localidades de la costa Este de Uruguay.

Palabras clave: pesquerías artesanales, etnografía, medios audiovisuales- representaciones sociales.

Abstract

The central purpose of this paper is to analyze how our ethnographic research, incorporating audiovisual media, was possible to perceive what is "being Fishworkers". We analyze the technique of audiovisual recording and production of the documentary as a way of representing a group of artisanal fishermen and in particular reflect on the process of building the ethnographic audiovisual story, beside its social and political implications. The results of this four-year process of "looking", "listen", recording, writing and editing, was an audiovisual and a book, "The Drowned World. An anthropological investigation of the mussel fishery in Piriápolis and Punta del Este" (D’Ambrosio, Lembo, Amato, Thompson, 2010). Both proposed parallel and polyphonic discourses, generated from fieldwork with workers in artisanal fisheries in two towns on the east coast of Uruguay.

Keywords: artisanal fisheries; ethnography; audiovisual media-social representation.

* Profesora Adjunta - Investigadora con Dedicación Total en el Centro Universitario de la Región Este- Universidad de la República (Uruguay). Doctoranda en Antropología Social del Instituto de Altos Estudios de la Universidad de San Martín (Argentina).Correo-e: treboles@gmail.com 


\section{Los estudios antropológicos de las pesquerías artesanales en la región ${ }^{1}$}

Han sido diversos los enfoques con los que se ha investigado a las poblaciones pesqueras tradicionales en las ciencias antropológicas, llegando a la actualidad con la consolidación de un campo subdisciplinar dentro de la antropología. La antropología marítima ha sido considerada como una subdisciplina de la antropología desde finales de la década del 70 y principios de la década del 80 (Pascual Fernández, 1999; Lembo, 2010; Rispoli, 2006), entendiendo a su campo de estudio como aquel que se centra en las sociedades o culturas que dependen del mar para su subsistencia. Bretón (1981), propuso definirla en sentido amplio, como una subdisciplina de la Antropología Social cuyo campo de estudio son las sociedades costeras, haciendo énfasis en la actividad productiva que las caracteriza (Lembo, 2010).

Uno de los primeros antecedentes de los estudios centrados en las pesquerías artesanales y en los grupos que trabajan los recursos costeros, ha sido el de Firth (1946) quien tomó varios conceptos teóricos provenientes de investigaciones realizadas en las sociedades agrarias y los aplicó a sus investigaciones con poblaciones pesqueras. Lo que inició las primeras discusiones en torno a la particularidad de las sociedades pesqueras y la necesidad de abordarlas desde un corpus teórico específico (De la Cruz y Arguello, 2006; Lembo, 2010). Las investigaciones de la década del 80 abordaban temas tales como la estructura familiar y las relaciones de parentesco, la tecnología y los medios de producción, la forma de adopción de las nuevas tecnologías, la cooperación y las actitudes frente a la modernización del medio por parte de los pescadores. Bretón señala que es el momento en el que se crean nuevos marcos analíticos para entender en profundidad la dinámica de las sociedades pesqueras con los aportes de otras corrientes, como la etnometodología, la ecología o los análisis marxistas y el interaccionismo simbólico (De la Cruz y Argüello, 2006). Desde esta última corriente ha primado el análisis de los aspectos cognitivos y la percepción del medio frente al análisis económico, la adaptación ecológica o las relaciones sociales de producción (Pascual Fernández \& Alegret, 2004). Si bien en nuestra investigación buscamos indagar tanto en la dimensión simbólica como en la perceptiva, económica y ecológica, en este artículo nos centraremos en aquellos aspectos que, mediante el medio audiovisual, surgieron para entender lo que es "ser un pescador artesanal".

A nivel regional, si bien las investigaciones sobre las pesquerías artesanales desde las ciencias antropológicas son bastante recientes, han contribuido al conocimiento de estos grupos sociales desde una perspectiva social, política, económica, simbólica y territorial y se han extendido numérica y geográficamente. Desde esta subdisciplina se han desarrollado múltiples conceptos para abordar a los diferentes grupos sociales que habitan el espacio costero.

Desde los aportes de los primeros trabajos a los estudios contemporáneos sobre las poblaciones costeras en la región se observan variaciones en los enfoques y en las temáticas definidas. Muchas de estas temáticas, surgen en el marco de una crisis ambiental acentuada que repercute sobre los recursos pesqueros y vuelve vulnerable a la franja costera. En el contexto de disputas por el territorio, en especial el marítimo- costero, de transformaciones en el modo de vida de las poblaciones pesque- 
ras tradicionales y precarización del mercado laboral. También se enmarcan en el desarrollo de políticas de manejo de recursos naturales en pos de la protección de los ecosistemas, el aumento de proyectos de desarrollo a gran escala, propuestas de desarrollo sustentable ${ }^{2}$ $y$ el crecimiento del turismo en las regiones costeras; e indirectamente lo que esto implica en términos de impactos económicos, físicos y socioculturales (Santana, 1997) y en los procesos de patrimonialización "desde abajo" (Mato, 2002) que resignifica conocimientos y prácticas sociales diversas. Estas temáticas y principalmente la última de ellas estará ligada al eje del audiovisual realizado y a la reflexión en este artículo.

\section{La pesca artesanal en la costa Este de Uruguay}

Las pesquerías artesanales son valoradas mundialmente por la selectividad de sus formas de extracción y por emplear a un mayor número de trabajadores que las pesquerías industriales. En Uruguay las autoridades encargadas de gestionar los recursos marinos manifiestan tener un interés en apoyar las pesquerías artesanales, por el uso más sustentable que posibilita las artes de pesca empleadas en dichas pesquerías.

La pesca artesanal en Uruguay se define, técnicamente, como aquella actividad realizada por uno o más pescadores cuyas capturas son realizadas con embarcaciones de menos de 10 toneladas de registro bruto (TRB), en el mar, en zonas próximas a la costa o en lagunas costeras (Defeo, et al., 2009).
Durante el transcurso de esta investigación, interactuando con las categorías nativas de pesca artesanal, desarrollamos la idea de pesquerías artesanales, entendiendo por este concepto a aquellas actividades vinculadas a la explotación y procesamiento de diversos bienes costeros, actividades desarrolladas por hombres y mujeres, tanto en tierra como en el mar, vinculadas directamente a la extracción de recursos marítimos para su consumo y comercialización, en torno a las cuales se ha desarrollado un conocimiento y apropiación del espacio marítimo-costero. En muchos casos se reconoce como espacio propio (que genera vínculos de arraigo y pertenencia) al espacio de trabajo común donde se desarrolla buena parte de las tareas en tierra, se fortalecen las redes sociales y se aprenden las bases del oficio. En este sentido, conversando con un pescador de mediana edad con diez años en la actividad, que observa mientras un grupo de pescadores encarna sus palangres ${ }^{3}$, me explica que siempre algo se aprende de estar conversando, de estar escuchando a los otros pescadores. Proceso que lleva unos cinco años para culminar en ser "un hombre de mano", lo que significa ser un hombre que tiene los conocimientos necesarios para salir a pescar. Por lo anteriormente señalado, a lo largo del artículo, cuando utilice el término de pesquería artesanal, incluyo en el mismo diversas actividades vinculadas a la explotación y procesamiento de diferentes bienes costeros. Actividades desarrolladas, por hombres y mujeres, tanto en tierra como en el mar. Y cuando me refiero a los pescadores artesanales utilizo la categoría de acuerdo al uso nativo de la misma, que atiende a la actividad desarrollada casi exclusivamente por hombres, de búsqueda y extracción de los recursos. El "pescador artesanal" es aquel que sale embar- 
cado en una chalana (que es el nombre que los pescadores dan a la embarcación), si bien desempeña otras tareas, esta es la que define su identidad laboral y muchas veces social.

Dentro de los pescadores artesanales se hace una diferenciación con los "buzos-mejilloneros", quienes también son conocidos como pescadores artesanales y cuya actividad principal es la extracción de mejillones mediante la técnica de buceo con narguile ${ }^{4}$. Con la particularidad que en determinados meses del año dejan las pesquerías de peces para pasar a realizar la extracción de mejillones, lo que deriva en otros conocimientos, entre los que se destaca, desde la percepción de los nativos, el buceo y el conocimiento de lo que sucede debajo del agua. Es habitual el relato del encuentro con restos de naufragios o especies variadas de peces y mamíferos marinos. Un espacio al que el grupo mayor de pescadores accede a través de los relatos de los buzos, de lo que ocasionalmente pueda engancharse en sus artes de pesca o también por el sonido; pues entre los pescadores mayores se menciona la técnica de acercar el oído al fondo de la embarcación para saber si se acerca algún cardumen de peces. Además, recientemente con la incorporación de las nuevas tecnologías, las imágenes trasmitidas por el sonar permiten un acercamiento al fondo marino.

En este artículo me centraré en el proceso de investigación de este oficio y de las pesquerías artesanales de otras especies marinas, o sea de la pesca artesanal en modo amplio. Son varias las actividades que se incluyen dentro de lo que los pescadores llaman "pesca artesanal": la actividad de "alistar y encarnar" las artes de pesca, diferentes según la especie a capturar, la navegación hacia las zonas de pesca y el proceso de captura (que puede implicar técnicas de buceo como es el caso de la pesquería de mejillones). Al regreso, en tierra, las actividades son: el desembarque de los pescados o moluscos, su procesamiento y acondicionamiento, la comercialización y/o la negociación con los intermediarios. Cada fase del trabajo se divide, con escasas excepciones, sexual y etariamente. La fase de extracción de los peces o moluscos es el centro de la práctica social de este oficio, desde la percepción nativa, y es desarrollada con escasas excepciones por hombres desde los 18 años a los 65, aproximadamente.

Es común que se haga referencia al hombre pescador como protagonista de la actividad. Una de las mujeres que trabajaba en la fase de procesamiento y comercialización, esposa de un pescador, hace referencia a lo sacrificado que es el trabajo de "ellos", a pesar de que su trabajo también implica grandes esfuerzos y largas jornadas de trabajo en la planta de procesamiento. Reunidas allí durante su jornada laboral me cuenta:

"(...) en el invierno con el tema de la pesca me vuelvo a trabajar con ellos, hago el trabajo de hombres, desenmallar (desenredar las redes de pesca), cinchar (empujar) con los trasmallos ${ }^{5}$ de pescado por arriba de la explanada (parte llana del muelle), encajonar, pesar, tener todo pronto para los camiones, que los camiones viene de Montevideo y trabajo con ellos" (Silvia, 30 años).

Entre las demás tareas se encuentra: el acondicionamiento de las artes de pesca a lo que se conoce como "alistar" que incluye la preparación de las líneas y acondicionamiento de anzuelos pues una vez que el pez muerde el anzuelo este se abre siendo necesario darle manualmente la forma original, el "desenmalle" que refiere a desenredar las redes de pesca, el "encarnado" que requiere poner la carnada en los anzuelos, 
la limpieza de las artes y de la embarcación, el procesamiento y la comercialización de la especie capturada, las cuales son desarrolladas, por lo general, por jóvenes de ambos sexos que se acercan a la actividad, pescadores mayores y mujeres adultas con alguna relación de parentesco o amistad con los pescadores y en algunos casos por los propios pescadores que luego se embarcarán. Como observamos estas últimas quedan en un segundo plano al momento de nominar la actividad.

Los pescadores artesanales de Piriápolis y Punta del Este presentan una amplia diversidad, algunos son pescadores "de tiempo completo" y otros "zafrales", nos dice un buzo-mejillonero, que solo se dedica a la pesquería del mingo ${ }^{6}$ durante la zafra de esta especie, en épocas en que no puede extraer mejillones. Otras diferencias se establecen de acuerdo a la relación con los medios de producción, a los roles dentro de la cadena productiva y al trabajo realizado en la embarcación.

El lugar de origen de los pescadores es un elemento que surge como diferenciador y esto se menciona en las conversaciones cotidianas. Aparece la idea de los "pescadores del oeste", que se acercan al balneario en épocas en las que el recurso se encuentra en la zona. Esta migración y nomadismo de los pescadores artesanales del Oeste hacia el Este, en Piriápolis, pareciera ser bastante reciente y es conocida como "la experiencia de los pescadores del oeste". Si bien los pescadores mayores cuentan que ellos, en la década del 40, migraban a las costas de Maldonado y Rocha para pescar tiburón (algunas veces contratados por el Estado) y es habitual el traslado en busca de los recursos, no se mencionó la migración numerosa de pescadores de Montevideo (Oeste) a Piriápolis (Este), en décadas anteriores a la de 1990.
Los conocimientos que se requiere para ser pescador abarcan diversas áreas. Las tareas pueden rotar y ser intercambiadas entre la tripulación, existiendo diferentes niveles de dificultad que, a medida que van incursionando en el oficio, se incorporan.

\section{Objetivos del audiovisual etnográfico sobre pesca artesanal}

De forma general, el cine en esta investigación fue concebido, siguiendo a Ardevol (1998), como técnica de investigación, modo de representación y medio de comunicación. Fueron varios los elementos e intereses que motivaron la incorporación del soporte y registro audiovisual en los diversos niveles de la investigación 7 . La pesquisa etnográfica implicó, entre otras actividades, el registro de los relatos de los primeros pescadores artesanales y de aquellos hombres y mujeres que actualmente trabajan en las pesquerías artesanales. Por un lado, el interés en el estudio de las pesquerías artesanales desde una perspectiva sociocultural, así como el estudio de la relación y conocimientos que los pescadores artesanales tienen del entorno marítimo costero, nos llevaron a los primeros acercamientos con los pescadores y sus familias.

Por otro lado, el registro de los oficios marítimos surgió del interés de algunos trabajadores en dar a conocer las problemáticas que enfrentan cotidianamente y la complejidad de las tareas que realizan. Desde los primeros encuentros con ellos fue recurrente que nos trasmitieran su preocupación por el desconocimiento de la sociedad en general hacia su actividad y en consecuencia la escasa valoración de su trabajo, percibiendo actitudes de rechazo 
y discriminación social por parte del resto de la población. Con la intención de modificar esta situación, un pescador de mediana edad, daba charlas en la escuela de sus hijos sobre la pesca artesanal, insistiendo en la necesidad de mostrar lo que es "ser pescador artesanal", proponiéndonos hacer registros audiovisuales de su trabajo para mostrarlo a "otros".

Algunos jóvenes tenían esta visión sobre las miradas de "los otros" hacia lo que algunos llaman "el círculo de la pesca", lo que es valorado como positivo en ciertos casos y en otros percibido como negativo (refiriéndose a la vinculación con el resto de la población del lugar). Para muchos, los pescadores se aíslan y marginan; para otros, los marginan por el tipo de actividad que realizan, por desconocimiento de su trabajo o por estereotipos que señalan una forma de ser pescador: que se alcoholiza y falta el respeto a las mujeres. Sobre este punto recordamos que en el proceso de la investigación, al encontrarnos con una persona con un cargo significativo a nivel político local nos decía: "yo ni loco dejó pasar a mi hija sola por allí (refiriéndose al pesquero)". Y por otro lado, a un nivel más institucional, pescadores mayores señalaban que no habían tenido ningún reconocimiento por su trabajo por parte de autoridades vinculadas a la actividad, a pesar de que dentro del grupo sí eran considerados como referentes y maestros. Es interesante al respecto, mencionar que el rol del patrón en algunos casos tiene una importancia más allá de lo que concierne a la actividad propiamente dicha. Pues muchas veces es consultado en busca de consejos ante situaciones de índole personal y de la esfera doméstica, su rol trasciende la esfera productiva. Lo que se enseña o se busca enseñar trasciende lo técnico, pues implica decisiones ante la vida en general, la salud, la familia, el trabajo y los amigos. Es común escuchar decir que el patrón es responsable por la vida de los otros marineros, lo que adquiere más trascendencia al tratarse de una actividad en la que, en muchas situaciones, se pone en riesgo la vida.

Algunos pescadores adjudicaban la situación de discriminación a diversos elementos que suponían podrían generar rechazo en "los otros": el olor a pescado que quedaba en su cuerpo (para lo cual muchos se bañaban con vainilla) y el consumo frecuente de bebidas alcohólicas entre algunos pescadores, que para muchos ayuda a enfrentar las noches frías de invierno; los chistes que se hacen entre compañeros mientras realizan las tareas de acondicionamiento de artes de pesca, que para muchos hace que el espacio no sea considerado como un lugar adecuado para mujeres. La discriminación se manifestaba, de acuerdo a alguno de los interlocutores, en actitudes cotidianas en centros educativos, espacios de recreación y en las políticas públicas de organización del puerto $^{8}$ - entre otros aspectos ${ }^{9}$. En síntesis, desde nuestra percepción, muchos pescadores buscaban generar otra representación e imagen del grupo, otras narrativas sobre la pesca artesanal, a la cual muchos consideran una actividad de toda la vida, así lo relata Larrosa:

\footnotetext{
“(...) mira, si te cuento la historia de cuando empecé a pescar, o empezamos los hermanos, yo creo desde que veníamos desde el vientre de mamá, estábamos pescando. Porque los abuelos eran pescadores, los tíos todos pescadores (...)" (Pescador artesanal, botero, salvavidas y buzo-mejillonero).
}

El otro elemento que motivó la realización del audiovisual fue el interés por explorar las técnicas audiovisuales de registro y producción etnográfica en una investigación en particular. Así como la intención de profundizar y buscar 
comprender y dar a conocer aspectos de la vida de hombres y mujeres que basan gran parte de su subsistencia en la explotación de los recursos costeros y desarrollando un relacionamiento y conocimiento del entorno costero.

Fue así que de la conjunción de dichas motivaciones surgió el audiovisual, al cual concebimos como un medio de comunicación para llegar a un público amplio. Coincidiendo en este sentido con Gallois (2001), en que uno de los objetivos del audiovisual etnográfico puede ser la comunicación social con el fin de desmontar preconceptos y estereotipos enraizados en el sentido común para establecer un nuevo campo de diálogo.

En relación a los administradores y gestores de los recursos naturales buscamos que el audiovisual mostrara desde la perspectiva de quienes trabajan en el mar, lo que ocurre con el manejo de los bienes naturales, hacer hincapié en su mirada y en cómo son afectados por los planes y políticas de manejo de los recursos (vedas, cuotas de extracción). Ello implicó reorientar los estudios basados en los recursos o bienes naturales hacia los sujetos que los trabajan. Este interés en las especies y no en los pescadores, lo observamos en los intereses de los trabajos publicados y las variables consideradas para determinar los momentos de vedas, que se regulan de acuerdo al proceso de crecimiento de las especies. Durante el fin del trabajo de campo, ya con el libro publicado, me reuní con un investigador del organismo público encargado de la gestión de los recursos marinos quien había sido entrevistado para el trabajo, para llevarle una copia del libro y del audiovisual. En el encuentro me comunica que era muy importante el trabajo que habíamos realizado porque estaban "desapareciendo", con una preocupación que me llamó particularmente la atención porque no había manifestado anteriormente tal preocupación por la situación del oficio. Al continuar la charla comprendí que no se refería a los pescadores sino que al recurso que trabajan.

Por otro lado, constatamos que en el área de estudio de esta investigación, la relación de los pescadores con las autoridades de los organismos de control de los recursos pesqueros está basada en la desconfianza por parte de los pescadores hacia las autoridades, esto fue expresado en diversas ocasiones por los pescadores artesanales en las que relataron hechos concretos en los que "probaron" que las vedas por marea roja eran un invento del organismo encargado de gestionar los recursos, por intereses económicos puntuales. Uno de estos acontecimientos fue la preparación e ingesta de una paella gigante en un momento de veda por marea roja, sin que nadie resultara afectado por la misma. Explicando que estas medidas estaban asociadas a intereses económicos de los políticos, para vender mercaderías importadas que competían con los productos de la pesca artesanal.

Asimismo entendimos al audiovisual como un medio para que los pescadores artesanales y sus familias generaran diversas representaciones y relatos sobre su trabajo, las actividades que desarrollan y todo lo que ello implica. Teniendo presente que dicha representación estaría mediada por nosotros, ya que desde la yuxtaposición de secuencias específicas, la inclusión de tomas particulares, la plataforma dada a ciertos protagonistas, los puntos de vista, y la manera en la cual se produce en el campo y el terminado estético que se le da después en el cuarto de edición derivarán, ya sea implícita 
o explícitamente, del punto de vista analítico del antropólogo (Henley, 2001).

Podemos enmarcar esta propuesta audiovisual dentro del cine etnográfico reflexivo, el cual tiene la característica que la cámara pasa a formar parte del propio proceso de investigación, captando la relación entre el investigador y su contexto de investigación (Ardevol,1998). Este tipo de cine será denominado por C. de France como exploratorio y se caracteriza por la incertidumbre, pues al no partir de un guión previo el investigador no sabe de antemano la estructura que tomará el producto. $Y$ por otro lado, se caracteriza por la adaptación al contexto de investigación, ya que la cámara no tiene el control sobre el contexto en el que se desarrolla la investigación, sigue la acción en lugar de dirigirla como sería en una película (Ardevol, 1998). En el caso que estamos analizando, en las instancias de trabajo embarcados y en tierra, la cámara acompañó las actividades de los pescadores mientras que en la entrevista la acción pudo ser guionada en cierta forma, si bien fueron entrevistas abiertas, teníamos varios objetivos (para la pauta de entrevista) planteados de antemano, entre ellos: "(...) indagar en el vínculo y la apropiación que establecen los pescadores y sus familias sobre el espacio costero, así como la idea de hacer visibles sus hábitos, costumbres y particularidades (...)" (D'Ambrosio, et al.; 2010:15).

\section{El registro audiovisual y el trabajo de campo}

A diferencia de otros audiovisuales, los filmes antropológicos pueden ser bastante inferiores en cuanto al trabajo de los profesionales cinematográficos pero consideramos que tendrán una calidad irremplazable del contacto real y primario entre la persona que filma y quienes son filmados (Rouch, 1995). Para intentar llegar a este resultado contábamos con el conocimiento y un relacionamiento previo con muchos de los pescadores artesanales que participaron del audiovisual. En los casos de los pescadores que no conocíamos con anterioridad, buscamos establecer encuentros previos a la realización del registro audiovisual para generar un vínculo de confianza. Siguiendo en este sentido a la obra de Prelorán, considerada como testimonial y de vertiente humanista, en la que el cineasta buscaba la realización de biografías fílmicas de personajes con los que se relacionaba íntimamente (Taquini; 1987:36). Por otro lado, para lograrlo debimos acordar las características formales que tendría el registro, tales como, el tipo de imagen que produciríamos, cual sería nuestro rol dentro de las tomas, quiénes participarían del documental, entre otros elementos que evaluamos con el equipo de investigación y producción (una antropóloga, un antropólogo- buzo y quien escribe), antes de iniciar el registro. Para ello consideramos cuáles serían las implicancias conceptuales de cada decisión teniendo en cuenta a su vez una serie de aspectos vinculados al uso de los medios audiovisuales en el trabajo etnográfico. En ese momento nos preguntamos para quién lo produciríamos, si estaríamos presentes en el cuadro, si utilizaríamos una voz en off, si saldría nuestra voz en los diálogos con los pescadores. Preguntas que tienen que ver con la forma de construir las etnografías, no solamente las audiovisuales sino también las escritas, con la forma de presentar los resultados de las investigaciones y de cómo construir los textos. Discusiones que en la antropología se han intensificado desde el giro interpretativista y lo que Marcus \& Fischer (2000) llaman la "crisis de la representación”. Como señala Cardoso de Oliveira: 
“(...) esta pregunta ha sido una constante en la llamada antropología posmoderna, un movimiento que (...) cuenta a su favor con el hecho de instalar al texto etnográfico como tema de reflexión sistemática, como algo que no puede ser tomado tácitamente (...)" (Cardoso de Oliveira, 1996:9).

En el caso de nuestra investigación buscamos que el antropólogo, entrevistador e interlocutor estuviera presente en el audiovisual para que detrás de los planos filmados se apreciara a la persona que los rodó. Pues como ya dijimos, entendemos que desde la construcción de los relatos de los informantes hasta la selección final de las imágenes, su montaje y edición, el investigador está presente en la etnografía audiovisual y buscamos que ello se visualizara en las imágenes producidas. El conocimiento generado es producto de la interacción de los sujetos con el investigador, del cruce e intercambio de ambas miradas y lecturas de los acontecimientos.

La otra interrogante y temor que se nos presentó, fue cuál sería la reacción de los pescadores ante la cámara, cómo podría modificar nuestros encuentros habituales, desde hacía ya varios años. La respuesta a esta pregunta la pudimos encontrar una vez que iniciamos las filmaciones, como veremos a lo largo de este texto.

Desde que la antropología tomó conciencia de la incidencia que causaban los antropólogos con su presencia en las prácticas cotidianas de sus investigados, este ha sido un tema de preocupación en la disciplina, primero para reconocer su existencia luego para convivir con ella, no siendo esta en desmedro de los resultados sino que por el contrario enriqueciéndolos.
Observamos que la cámara incidió de diversas formas, por un lado, evidenciamos lo que menciona Henley (2001), que la cámara puede servir para dar al antropólogo una razón de estar, siendo más entendible para sus anfitriones el ver a un antropólogo con una cámara, pues se sabe que está trabajando para una película mientras que antes su presencia era una incógnita o podría ser elemento de sospecha.

Si bien nuestra idea de realizar un audiovisual coincidió, como mencionamos en un comienzo, con la de un pescador que buscaba registrar las actividades de la pesca artesanal, uno de los primeros pescadores a quien invitamos a participar y propusimos filmar se negó rotundamente. Durante la planificación de la salida de campo elaboramos una lista de entrevistados, con quienes ya habíamos compartido algunos encuentros pero no habíamos hablado de la posibilidad de realizar un registro audiovisual. Por las características de la personalidad, sus experiencias y su elocuencia en los relatos de las mismas, Pérez era uno de los entrevistados seleccionados. Él fue pescador, carpintero de ribera y marino mercante, todas estas actividades dejaron una experiencia en relación al mar y a la vida en general, sus palabras nos trasmitieron desde un primer momento lo que era para él "ser pescador artesanal", desde la primera vez que fuimos a su casa. La cual había construido al fondo de la casa conyugal (que debió abandonar por problemas de convivencia con su esposa) siguiendo la forma de un camarote de barco mercante, por eso nos explicaba que los utensilios de la cocina estaban todos colgados de ganchos, tal como se hacía en los barcos para que los mismos no se volcaran al piso. Su descripción de su primer embarcación llamada "Valentina", en honor a la primera mujer rusa que fue al espacio. Además 
sus reflexiones sobre su vida como pescador, marino y carpintero, pero también sobre la situación de las pesquerías lo que llevaba a que muchas veces en el pesquero se lo conociera como "el filósofo".

Frente a su negativa de participar apareció nuestro desánimo y tristeza, sus argumentos tenían que ver con el uso contemporáneo dado a las imágenes y la frivolidad de los medios de comunicación. Introducía el tema del tipo de representación y el destinatario de la misma. Para revertir esta situación debimos desmarcarnos en los hechos de esas otras situaciones de registro audiovisual y acompañar el proceso de aceptación de la cámara por parte del pescador, quien frente a su negativa nos sugirió a otro pescador que tenía, a su juicio, historias más "espectaculares" para contar, entre estas el relato de un naufragio del que había participado (anteriormente registrado y narrado por escritores de renombre en el medio nacional). En aquellos encuentros, Pérez estuvo presente pues el pescador vivía temporalmente en la casa contigua a la suya, demostrando un interés creciente en el trabajo y en las temáticas abordadas en las charlas. Estas estaban vinculadas a aspectos de la navegación, el aprendizaje del oficio, los factores económicos y políticos que incidían en la actividad y la práctica del oficio en general. Pérez interrumpía por momentos al otro pescador para compartir sus experiencias y finalmente propuso su casa como espacio para nuestros encuentros. Expresándonos que él tenía muchos más conocimientos que su vecino.

Visualizamos que el objetivo de la investigacióntantas veces confuso para los interlocutores del estudio- debía ser explicitado y comprendido para que el entrevistado aceptara nuestra intromisión con una cámara filmadora.
Por otro lado, es importante tener en cuenta aquellos interlocutores que anteriormente ha tenido el grupo con el que trabajamos, pues es importante marcar la diferencia o la cercanía. En el caso de algunos buzos mejilloneros, sus anteriores interlocutores con cámara habían sido documentalistas extranjeros y periodistas en busca de una nota exótica. Quienes no habían regresado para entregar el producto finalizado a los pescadores, a pesar de haberse comprometido a esto.

En el caso de los pescadores artesanales, los medios de comunicación se habían acercado en momentos de cambios en las normativas, donde como nos relata José, era una oportunidad para reclamar sus derechos públicamente y recuerda aquel momento en "La Floresta":

“(...) a partir que se creó un Decreto de Ley, para que se nos den los implementos de seguridad... estee pero increíblemente tuvimos que perder cuatro compañeros de un saque para que se instrumentara la Ley... salir por la televisión, meter jeta, me acuerdo vino una muchacha rubia a hacerme un reportaje a mí, si me va a pasar lo que digo hago declaraciones sino no".

En muchos casos los encuentros eran tomados con más entusiasmo, expectativa y se destacaban los deseos de comunicar, mientras que en otras situaciones la cámara parecía no modificar los encuentros. La primera situación se observó en aquellos pescadores que tenían una actitud militante en relación a la pesca artesanal, destacando un análisis más detallado de las condiciones de vida de los trabajadores del sector. Y por otro, en reuniones con pescadores retirados de la actividad, con ganas de registrar sus anécdotas e impresiones sobre las pesquerías artesanales y lo que ha sido su vida como pescador artesanal. Aquí debimos conversar sobre las expectativas que había generado la investigación. Así ocurrió 
con "el colorado", pescador de ochenta años, que algo enojado me reclamaba cuando le expliqué que no tenía las herramientas suficientes para llevar a cabo algunas de sus propuestas, entre estas crear una escuela de pesca en la costa. Pues este era uno de los elementos que identificaba estaba faltando para evitar que los pescadores salieran embarcados sin conocimientos previos y consideraba que como era una universitaria tendría alguna vinculación con los políticos.

Otros entrevistados percibieron al documental como un espacio para hacer reivindicaciones y planteos en relación a las políticas de gestión de los recursos marítimos (como cambios en las vedas y cupos de captura), detallando en qué se ven ellos perjudicados con estos cambios, lo que muchas veces no es considerado por las autoridades. En estos casos observamos que por momentos nos hablaban a nosotros mientras que en otros se dirigían directamente a la cámara, como hablando a la persona que podría ver la grabación.

Durante los registros audiovisuales de las entrevistas a buzos-mejilloneros, mientras conversábamos sobre las etapas del proceso de extracción y posterior comercialización de mejillones, surgía muchas veces una problemática asociada a que los permisos de extracción habían sido restringidos por la DINARA (Dirección Nacional de Recursos Acuáticos), al considerar al recurso como plenamente explotado. Dichos cupos habían sido otorgados a las embarcaciones y no a los trabajadores, lo que redundaba a que el dueño de la embarcación que tenía el permiso, arrendará la embarcación y el permiso al buzo-mejillonero. Esto implicaba para el mejillonero tener un costo más alto por cada salida, y llevaba muchas veces a que este no respetara las cuotas de extracción, para así compensar el costo de arrendamiento de la embarcación y en cierta forma era un pago indirecto por el acceso al permiso ${ }^{10}$.

Otro de los aspectos que preocupa a muchos pescadores con años en la actividad es el tipo de embarcaciones que se emplean para la pesca y la forma en que son construidas. Un día en el taller de Pérez, quien hasta hace pocos años estaba ejerciendo como carpintero de ribera, Pedro, otro pescador de mediana edad, señaló que:

\begin{abstract}
"(...) la primera cosa que hay que cambiar, para empezar a pensar en una renovación de una mejor condición de trabajo es llegar a ese tipo de embarcaciones, porque tenés un mayor ahorro de combustible, más seguridad de navegación, y si tenés más seguridad tenés más protección, entonces mientras no tomemos conciencia los pescadores y reclamemos. Y lamentablemente solo con que traigan una embarcación bien pintada el pescador te dice mira que linda, mira que bárbara y no hay ninguna norma científica, que pueda sostener como está sosteniendo Pérez ahora este relacionamiento entre lo que es la fuerza, como se desliza y todo lo que él explico (...)".
\end{abstract}

En otros casos la cámara fue utilizada para dejar plasmado todo aquello que de otra forma se perdería. Como en el caso de algunos pescadores mayores que manifestaban su preocupación porque sus conocimientos se perderían al no haber nuevos aprendices del oficio, en particular la carpintería de ribera. Pérez nos contó que había intentado generar un espacio de aprendizaje de dicho oficio, pero el mismo no había funcionado.

Por otra parte, el equipo de registro fue un atractivo para algunos pescadores jóvenes, quienes se involucraron en las instancias de conversación e intercambio de relatos, junto a pescadores mayores, que aprovecharon esos 
momentos para trasmitir aspectos vinculados al oficio y a la vida del pescador artesanal.

Sin embargo, en algunos momentos la cámara, parecía no incidir notoriamente en los encuentros, sobre todo cuando estos eran casuales y no programados, ni acordados previamente como ocurría en muchas de las instancias de entrevista, por ejemplo cuando los mismos se desarrollaban en el puerto o el pesquero.

Otro de los desafíos que debimos afrontar fue: ¿cómo lograr la representación de un grupo heterogéneo? Como mencionábamos anteriormente, el grupo de pescadores artesanales no es homogéneo, sus diferencias están asociadas a sus diversas trayectorias personales y distintas motivaciones que los han llevado a elegir o dedicarse al oficio, así como los roles que han ocupado dentro de la cadena productiva, pues no todos han sido propietarios de los medios de producción (embarcación y equipos) y esto ha repercutido en los intereses de cada uno y en las relaciones sociales que han establecido. Se diferencian también en cuanto a posiciones frente a aspectos vinculados a la gestión, procesamiento, comercialización del recurso y su adaptación a los cambios. A su vez se observan diferencias claras entre generaciones distintas y momentos diferentes del país, entre las localidades y, más concretamente, en las políticas vinculadas a la extracción del recurso. Lo que llevará a evaluar de diversas formas su relación con la actividad, los pares y con otros actores sociales, que interactúan cotidianamente con ellos, como intermediarios, el vendedor final del producto, las autoridades que gestionan el recurso, quienes gestionan las zonas de extracción, los pobladores del lugar y los turistas (D'Ambrosio, 2010:53). Ello implicó un esfuerzo por incorporar los diversos puntos de vista en el producto audiovisual final, optando metodológicamente por introducir la heterogeneidad en el material audiovisual y dar cuenta de la complejidad.

En el proceso de investigación y edición el guión general fue modificado en relación a lo que en un principio habíamos imaginado, y lo construimos de acuerdo a las temáticas que los propios pescadores resaltaban en los encuentros. En este sentido, es interesante reflexionar sobre la incidencia del registro audiovisual en sus relatos y en las temáticas que priorizaban y destacaban por momentos, en el proceso de construcción del relato etnográfico.

Por ello nos propusimos reflexionar sobre el proceso de representación y la incidencia de la cámara en los entrevistados, evaluando en qué sentido aconteció lo que destacaba Barthes: "(...) cuando me siento observado por el objetivo, todo cambia, me constituyo en el acto de posar, me fabrico instantáneamente otro cuerpo, me transformo por adelantado en imagen" (1998:43). Lo que nos llevó a retomar algunas discusiones teóricas más amplias de la antropología, en torno a las representaciones sociales y a la construcción de los relatos. Uno de estos temas es el de la objetividad y subjetividad en el registro y representación audiovisual. Observamos que incluso los pioneros del cine documental, algunos situados bajo el paradigma positivista como Flaherty, reconocen que la selección de las imágenes subsiste, a pesar de que postulaban que era posible, con el uso de la técnica audiovisual, captar con la cámara la vida bajo la forma en que se vive. Esta temática ha sido debatida en la historia de las ciencias sociales, frente a la idea del positivismo de que la observación sería neutra y externa -lo que permitiría la objetividad científica en la aprehensión del objeto de 
conocimiento "tal cual es"- y los resultados de la investigación de acuerdo a este paradigma podrían, en determinadas condiciones, ser objetivos; el paradigma del interpretativismo dio luz al plantear que los fenómenos socioculturales no pueden ser estudiados como lo es la conducta animal, la diferencia de estos, la marca de los diversos sentidos que tienen las acciones para el hombre, la forma de acceder a su estudio es la vivencia, por lo que la participación se presenta como imprescindible; como "condición sine qua non del conocimiento de un sistema cultural (...) Las herramientas son, pues, la experiencia directa de los órganos sensoriales y la afectividad que, lejos de empañar, esclarecen y explican la dinámica cultural" (Guber, 1991:177).

Observamos que en cada una de estas etapas las vivencias del investigador incidieron en los resultados. Al adquirir relevancia, el hecho de que:

Imagen 1

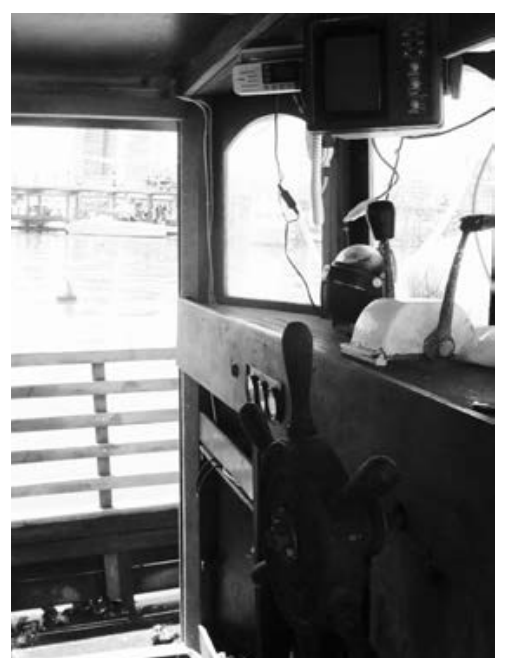

Cabina de embarcación pesquera artesanal (Fotografía de la autora)
"(...) como participante (lo parezca o no) en el proceso de autoconcientización cultural y reforzamiento sociopolítico, el usuario antropológico de los medios tiene cierto control sobre los términos de su participación. Puede conscientemente planear documentar actividades para reforzar, o apoyar aquellos aspectos del fenómeno documentado que promociona el reforzamiento de su tema a reflejar, controlar y transformar de acuerdo a sus propias luces los aspectos culturales, políticos y materiales de la realidad enfocada" (Turner,1991:21).

Otro de los aspectos que se destacó en el proceso de investigación, vinculado al anterior, fue la implicancia política y ética del investigador. Temática que ha sido abordada por diversos investigadores, en este sentido, en el contexto sociocultural en el que se desarrolló nuestro estudio, el filmar el trabajo de los trabajadores artesanales en las pesquerías tiene una significación en el sentido de la posibilidad de conferir valor (en este caso pequeño, pero existente); que a su vez plantea la interrogante de quiénes son los que acceden comúnmente a producir las imágenes que circulan en los medios de comunicación.

\section{Imagen 2}

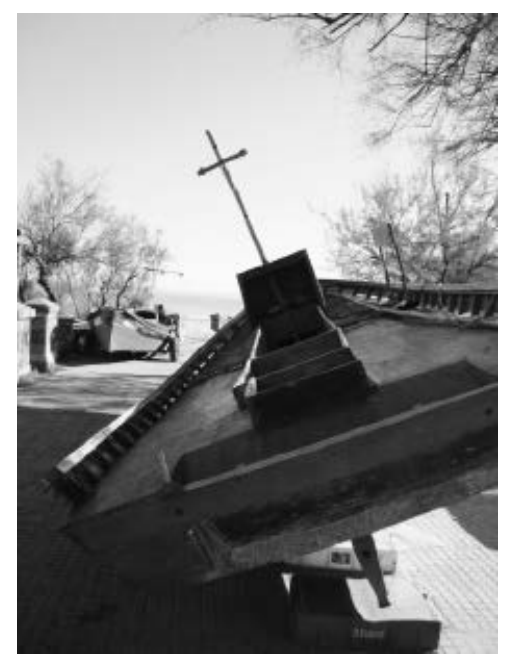

Embarcación pesquera reparada 


\section{Imagen 3}

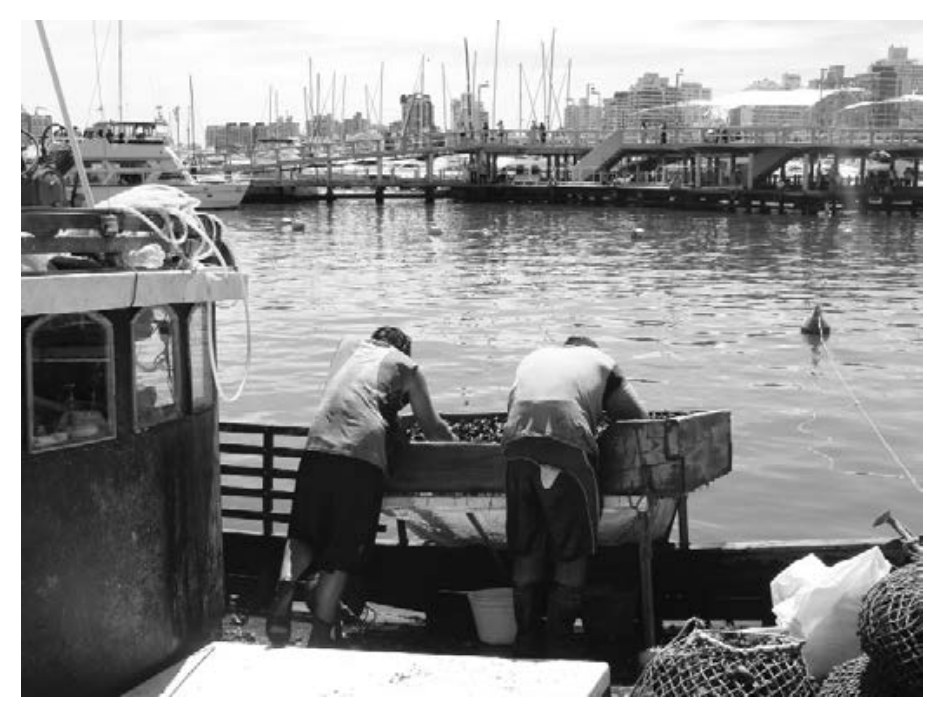

Trabajando en la embarcación, en Puerto de Punta del Este (Fotografía de la autora)

\section{Consideraciones finales}

En este artículo profundizamos en la experiencia de los investigadores en el proceso del registro audiovisual con fines de investigación antropológica y su posterior edición. Intentamos hacer un aporte a la reflexión del trabajo etnográfico a partir del análisis de un caso en particular.

La propuesta inicial de investigación etnográfica audiovisual, fue profundizar en lo que implica ser pescador artesanal y en los aspectos sociales, políticos y económicos de la actividad productiva, sus conocimientos del medio marino, la división sexual y etaria del trabajo, entre otros elementos vinculados a la actividad y al contexto en el que se desarrolla. En el transcurso de la investigación, como señalamos, se fueron incorporando nuevas temáticas y priorizando aquellas que los pescadores destacaban en sus relatos.
Nuestro estudio se centró en un grupo de pescadores artesanales de la costa Este de Uruguay y surgió por iniciativa de algunos pescadores artesanales que buscaban dar a conocer y revalorizar su oficio, al mismo tiempo que existía nuestro interés por conocer los oficios marítimos y explorar las técnicas de producción audiovisual en antropología social. En relación con este último aspecto, buscamos que el artículo sea un aporte a la discusión sobre la relevancia de los usos de los medios audiovisuales y sus implicancias. Estudiando las diversas formas de trabajar con el audiovisual etnográfico y las diferentes formas de incorporarlo en la investigación etnográfica. En el planteamiento de estas discusiones ahondamos en aspectos que hacen a la práctica etnográfica en forma general, pues el creciente uso "reflexivo" de los medios audiovisuales está en consonancia con el giro inter- 
pretativista y lo que se ha llamado "antropología comprensiva" que destaca una reflexión sobre el trabajo de campo y la escritura etnográfica (Marcus \& Fischer, 2000:39).

\section{Consideramos que el abordaje diseñado para la investigación que analizamos en este artículo,}

permitió dar visibilidad a muchos de los actores involucrados con las pesquerías artesanales, sus prácticas y discursos en torno al acceso y uso de los bienes marinos y de modo más amplio a lo que es "ser pescador artesanal".-

\section{Notas}

\footnotetext{
${ }_{1}^{1}$ Agradezco al colega y amigo Dr. José Colaço por su revisión de la versión preliminar de este manuscrito y sus valiosos aportes al mismo.

${ }^{2}$ Este concepto ha sido abordado desde diversas perspectivas teóricas, teniendo connotaciones diversas, lamentablemente no podremos extendernos en este aspecto. Para una profundización ver los trabajos de Pierri (2001), "Historia del concepto de desarrollo sustentable"; Tommasino (2001), "Sustentabilidad rural: desacuerdo y controversias"; Foladori \& Tommasino (2001), "El enfoque técnico y el enfoque social de la sustentabilidad".

${ }^{3}$ Arte de pesca que consiste en una línea de cuerda con ramales de otras líneas que tienen un anzuelo en su extremo cada una.

${ }^{4}$ Consiste en el buceo (en este caso, a 6 o 7 metros de profundidad) con aire administrado desde la superficie por un motor (que comprime el aire), a través de una manguera de jardín (sin regulador de aire).

${ }^{5}$ Arte de pesca que consiste en tres redes, la del medio más tupida que las otras.

${ }^{6}$ Denominación que tiene la corvina juvenil.

${ }^{7}$ La investigación fue llevada a cabo por un equipo de antropólogos, intercalando en el proceso de cuatro años momentos de trabajo individual con instancias grupales. Los colegas con quienes compartí las instancias grupales fueron: Victoria Lembo y Blas Amato, juntos funcionamos como equipo en las etapas de registro, sistematización y edición del material audiovisual y el libro "El Mundo Sumergido. Una investigación antropológica de la pesquería del
}

mejillón en Piriapolis y Punta del Este". Se sumaron al proceso de investigación, en algunas instancias, y a la escritura los colegas Diego Thompson y Carla Peña.

${ }^{8}$ En 1996 se realizó una reforma de ampliación del Puerto de Piriápolis, con el objetivo de convertirlo en Puerto Deportivo, con amarre a muelle para 70 embarcaciones deportivas, capacidad para 50 embarcaciones deportivas varadas en la explanada; lugar para 5 embarcaciones en tránsito; 10 embarcaciones de pesca artesanal y un muelle comercial para un Ferry de hasta $80 \mathrm{~ms}$ de eslora. La planificación del puerto fue hecha priorizando las actividades deportivas frente a las de pesquería artesanal. Así surge el Pesquero Stella Maris, a unos 600 metros del Puerto, desde allí se despachan cerca de 20 embarcaciones pequeñas, llamadas "chalanas" (D'Ambrosio, 2006:8).

${ }^{9}$ Debido a su complejidad y a que excede el tema de este artículo no los desarrollaremos.

${ }^{10}$ En otro trabajo (D'Ambrosio, 2010) analicé como las medidas tomadas por el Gobierno en relación al recurso inciden negativamente sobre el objetivo que persigue el Gobierno, en relación a la protección del recurso. Por ejemplo, permitiendo el ingreso al país de mercadería producida por medio de cultivo a muy bajo costo, lo que redunda en que los pescadores artesanales deban bajar el precio de su producto, teniendo que -para continuar con su rentabilidad- extraer una mayor cantidad de lo autorizado en cada salida. 


\section{Referencias bibliográficas}

Ardevol, E. (1998). "Por una antropología de la mirada: etnografía, representación y construcción de datos audiovisuales". Revista de Dialectología y Tradiciones Populares del CSIC. Madrid: Perspectivas de la Antropología Visual.

Barthes, R. (1998). La cámara lúcida. Notas sobre la fotografía. Barcelona: Paidós.

Cardoso de Oliveira, R. (1996). "El trabajo del antropólogo: mirar, escuchar, escribir”. Revista de Antropología, Vol. 39, № 1. Sao Paulo: Facultade de Filosofía, Letras e Ciencias Humanas, Universidade de Sao Paulo.

D’Ambrosio, L., Lembo, V., Amato, B. \& Thompson, D. (2010). El mundo sumergido: una investigación antropológica sobre la pesquería del mejillón en Piriapolis y Punta del Este. Montevideo: Ediciones de FHCE.

Defeo, O., Horta, S., Carranza, A., Lercari, D., De Alava, D. Gómez, J., Martínez, G., Lazoya, J. \& Celentano, E. (2009). Hacia un manejo ecosistémico de pesquerías: áreas marinas protegidas en Uruguay. Montevideo: Facultad de Ciencias-DINARA.

De la Cruz, J. L. \& Argüello, F. J. (2006). "Paradigmas de la antropología en el estudio de las sociedades costeras”. Mad, № 15. Santiago: Departamento de Antropología de la Universidad de Chile, Santiago. Disponible en: http:// www.facso.uchile.cl/publicaciones/ mad/15/delacruz.pdf Fecha de consulta: 20 de diciembre de 2015

Gallois, D. (2001). "Parceria e comunicao por meio de imagens: entrevista com Dominique Tilkin Gallois". Cadernos de Antropologia e imagem, Vol. 12, № 1. Río de Janeiro.

Guber, R. (1991). El Salvaje metropolitano. Buenos Aires: Legasa.

Henly, P. (2001). "Cine etnográfico: tecnología, práctica y teoría antropológica". Desacatos, № 8.

Marcus, G. \& Fischer, M. (2000). La antropología como crítica cultural. Buenos Aires: Amorrortu.

Mato, D. (2002). "Des-fetichizar la 'globalización': basta de reduccionismos, apologías y demonizaciones, mostrar la complejidad y las prácticas de los actores". En Estudios Latinoamericanos sobre Cultura y transformaciones sociales en tiempos de globalización, 2. Buenos Aires: CLACSO.

Pascual Fernández, J. J. \& Alegret, J. L. (2004). "Estado actual de la antropología de la pesca en España”. Museu de la Pesca.

Pierri, N. (2001). "Historia del concepto de desarrollo sustentable". En Pierri, N. \& Foladori, G. (eds.). ¿Sustentabilidad? Desacuerdos sobre el desarrollo sustentable. Trabajo y capital. Montevideo.

Rispoli, F. (2006). "Trabajar de pescador. Aportes desde la antropología marítima”. Ponencia en el 8ํㅡㄹ Congreso Argentino de Antropología Social, Universidad Nacional de Salta. Disponible en: http://www.fcnym.unlp.edu.ar/catedras/mtiantropologica/Trabajar\%20 de\%20pescador.pdf Fecha de consulta: 20 de diciembre de 2015.

Rouch, J. (1995). "El hombre y la cámara". En Ardevol, E. \& Pérez, L. (eds). Imagen y cultura. Perspectivas del cine etnográfico. Granada: Diputación Provincial de Granada.

Rubio- Ardanaz, J. (2003). "La antropología de la pesca, campo y oportunidades para la investigación antropológica: perspectivas desde el formalismo, sustantivismo y materialismo". Zainac, № 25. España.

Santana, A. (1997). "Antropología y turismo: ¿nuevas hordas, viejas culturas?". Barcelona: Ariel.

Sanz, L. (1983). "En torno a la penetración de las relaciones capitalistas de producción en la pesca costera gallega". Disponible en: http://www.mapa.es/ministerio/pags/biblioteca/revistas/pdf_ays/ a028_08.pdf Fecha de consulta: 20 de diciembre de 2015.

Taquini, G. (1987). "Los documentales de Jorge Prelorán: un cine antropomórfico", En Bossi, J. J. (comp.). Cine documental autobiográfico de Jorge Prelorán. Buenos Aires: Búsqueda.

Turner, T. (1991). "Representing, Resisting, Rethinking. Historical Transformations of Kayapo Culture and Anthropological Consciousness". En Stocking, G. (ed.). Colonial Situations. Essays on the Contextualization of Ethnographic Knowledge. History of Anthropology, Vol. VII. Madison: The University of Wisconsin. 